\title{
Mecanismo Genético de Resistência em Três Cultivares de Algodoeiro a Xanthomonas axonopodis pv. malvacearum
}

\author{
Carla Zandoná ${ }^{1}$, Yeshwant R. Mehta ${ }^{1}$, Ivan Schuster ${ }^{2}$, Priscila F. R. Alves ${ }^{1}$, Cleide A. Bomfeti, \\ Kelen R. P. Bibanco', Rosana B. Silva \& Lucilene P. Lopes \\ ${ }^{1}$ IAPAR, Cx. Postal 481, CEP 86001-970, Londrina, PR.; ${ }^{2}$ COODETEC, Cx. Postal 301, CEP 85818-660 \\ Cascavel, PR, e-mail: yrmehta@iapar.br
}

(Aceito para publicação em 27/10/2005)

Autor para correspondência: Yeshwant R. Mehta

ZANDONÁ, C., MEHTA, Y.R., SCHUSTER, I., ALVES, P.F.R., BOMFETI, C.A., BIBANCO, K.P., SILVA, R.B. \& LOPES, L.P. Mecanismo genético de resistência em três cultivares de algodoeiro a Xanthomonas axonopodis pv. malvacearum. Fitopatologia Brasileira 30:647-649. 2005

\section{RESUMO}

A mancha angular do algodoeiro (Gossypium hirsutum) causada por Xanthomonas axonopodis pv. malvacearum (Xam) é uma doença de importância econômica para o Brasil, e sua severidade depende de fatores climáticos e da cultivar. A doença não é controlada por produtos químicos sendo que seu controle depende da utilização de sementes sadias, e resistência varietal. DeltaOPAL, EPAMIG Liça, e Fibermax 986 são importantes fontes de resistência a Xam, pois além de resistência, apresentam boas características agronômicas. O objetivo do presente trabalho foi estudar o mecanismo de resistência à mancha angular envolvendo cruzamentos entre as três cultivares resistentes e a suscetível BRS Ita 90, em casa de vegetação. Populações parentais, F1 e F2 foram avaliadas após inoculação com um isolado agressivo de Xam. As três cultivares apresentaram mecanismos diferentes de resistência. Nas cultivares DeltaOPAL e EPAMIG Liça a resistência é conferida por um gene dominante, enquanto que em Fibermax 986, a resistência é dada por dois genes dominantes, independentes e complementares.

Palavras-chave adicionais: Gossypium hirsutum, mancha angular, bacteriose.

\begin{abstract}
Genetic mechanism of resistance to Xanthomonas axonopodis pv. malvacearum in three cotton cultivars

Angular leaf spot of cotton (Gossypium hirsutum) caused by Xanthomonas axonopodis pv. malvacearum (Xam) is an economically important disease in Brazil. The severity of the disease depends on climatic conditions and the type of cultivar. The disease is not satisfactorily controlled by the use of chemicals, but with control depending basically on the use of healthy seed and resistant varieties. Cultivars DeltaOPAL, EPAMIG Liça and Fibermax 986 are the best sources of resistance to Xam, since besides resistance, these cultivars possess desirable agronomic characteristics. The objective of the present investigation was to verify the mechanism of resistance to angular leaf spot in these three resistant cotton cultivars by crossing them with the susceptible cultivar BRS Ita 90, under glasshouse conditions. Parental populations F1 and F2 were evaluated in the glasshouse after inoculation with an aggressive isolate of Xam. All the three of the cultivars revealed different mechanisms of resistance. In cvs. DeltaOPAL and EPAMIG Liça, resistance is governed by one dominant gene, whereas in cv. Fibermax 986, the resistance is governed by two dominant, independent and complementary genes.
\end{abstract}

Additional keywords: Gossypium hirsutum, angular leaf spot, black arm.

A mancha angular do algodoeiro (Gossypium hirsutum L.) causada por Xanthomonas axonopodis pv. malvacearum Smith (Dye) (Xam) é uma doença de importância econômica para o Brasil e sua severidade depende de fatores climáticos e da cultivar. O patógeno é transmitido por sementes infetadas. No entanto, até agora não existem métodos apropriados para erradicar a bactéria da semente. A doença não é satisfatoriamente controlada por produtos químicos, sendo que, seu controle depende de sementes sadias e resistência varietal. A doença pode ser controlada com o uso de cultivares resistentes. Algumas cultivares resistentes, tais como DeltaOPAL, EPAMIG Liça e Fibermax 986, foram identificadas em casa de vegetação e no campo (Freire et al., 1999; Cia et al., 1999; Mehta et al., 2005). Aliadas à resistência, essas cultivares possuem características agronômicas desejáveis e são amplamente cultivadas nos estados de Mato Grosso, Goiás, São Paulo e Paraná. O objetivo do presente trabalho foi estudar o mecanismo de resistência à mancha angular envolvendo cruzamentos entre as três cultivares resistentes e a suscetível BRS Ita 90, em casa de vegetação, a fim de auxiliar os programas de melhoramento genético que visam criar novas cultivares com resistência a esta doença.

\section{Semente genética e cruzamento}

As cultivares de algodoeiro DeltaOPAL, EPAMIG Liça e Fibermax 986 (resistentes) e a cultivar BRS Ita 90 (suscetível) foram selecionadas para os cruzamentos. Para este fim, uma planta típica de cada cultivar foi autofecundada para produzir semente básica para os cruzamentos. As plantas foram cultivadas em vasos de $30 \mathrm{~cm}$ de diâmetro contendo 
solo esterilizado, em casa de vegetação. Sementes de todas as populações juntamente com os progenitores foram multiplicadas em todas as fases do trabalho para evitar o efeito da idade de sementes na expressão dos sintomas da doença.

Cruzamentos dialélicos foram realizados entre as quatro cultivares. Nos cruzamentos 8-10 maçãs foram obtidas. Vinte sementes de cada F1 foram semeadas e as plantas foram autofecundadas para obter sementes da geração F2.

\section{Inoculação e avaliação}

Em todas as inoculações um único isolado agressívo de Xam (No. 13403), da coleção do IAPAR foi utilizado e o inóculo foi ajustado aproximadamente a 1,0 x $10^{6} \mathrm{ufc} / \mathrm{ml}$. Aos 25 dias de idade, as populações segregantes e dos progenitores foram inoculadas utilizando-se a técnica de palito de dente previamente embebidos em suspensão bacteriana e foram incubadas em câmara de crescimento ajustado a $21^{\circ} \mathrm{C}$ e $95 \%$ de umidade relativa do ar por 24 h (Mehta et al., 2005). Após este período as plantas inoculadas foram transferidas e casualizadas em casa de vegetação. A severidade da infecção foi avaliada oito dias após a inoculação utilizando uma escala visual de 0-3 onde; $0=$ nenhum sintoma da doença; 1 = encharcamento ao longo do ferimento, $<2 \mathrm{~mm}$ de largura e sem clorose; 2 = encharcamento $2-5 \mathrm{~mm}$ de largura e sem clorose; e $3=$ encharcamento $>5 \mathrm{~mm}$ de largura e estendendo a nervuras e provocando clorose e ou morte da folha (Mehta et al., 2005). A reação das plantas foi confirmada através de reinoculação e reavaliação. A severidade de infecção foi traduzida da seguinte forma: $0,0=$ resistente (reação não compatível); 1,0 a 3,0 = suscetível (reação compatível) (Mehta et al., 2005). Os dados foram analisados utilizando-se o método de qui-quadrado.

Todas as plantas da cv. resistente DeltaOPAL mostraram reação resistente dez dias após a inoculação com um isolado agressivo de Xam (Freire et al., 1999; Cia et al., 2000; Mehta et al., 2005). Similarmente, todas as plantas da cv. suscetível BRS Ita 90, mostraram reação suscetível. As plantas da geração F1 mostraram resistência completa enquanto que, as plantas da geração F2 segregaram entre resistentes e suscetíveis. A hipótese para a razão de segregação de 3R:1S foi aceito pelo teste de $\chi 2(p=94,91)$ (Tabela 1).

Quanto ao cruzamento EPAMING Liça x BRS Ita 90, na inoculação artificial todas as plantas da cultivar EPAMIG Liça e da geração F1 foram resistentes, sendo que entre as 129 plantas segregantes da geração F2, 96 foram resistentes e 33 suscetíveis (Tabela 2.). A hipótese de razão de segregação

TABELA 1 - Teste de qui-quadrado para os padrões de segregação para área foliar infetada por Xanthomonas axonopodis pv. malvacearum (Xam), baseado nas reações dos progenitores e das populações segregantes do cruzamento DeltaOPAL X BRS Ita 90

\begin{tabular}{|c|c|c|c|c|c|c|c|c|c|}
\hline \multirow{3}{*}{ População } & \multirow{3}{*}{$\begin{array}{l}\text { Reação } \\
\text { foliar* }\end{array}$} & \multirow{3}{*}{$\begin{array}{l}\mathrm{n}^{0} \text { total de } \\
\text { Indivíduos }\end{array}$} & \multirow{3}{*}{$\begin{array}{c}\text { Razão teórica } \\
\text { (R:S) }\end{array}$} & \multicolumn{4}{|c|}{$\begin{array}{l}\text { Número de indivíduos em } \\
\text { cada categoria de infecção** }\end{array}$} & \multirow{3}{*}{2} & \multirow{3}{*}{ Prob \% } \\
\hline & & & & \multicolumn{2}{|c|}{ Observados* } & \multicolumn{2}{|c|}{ Esperados* } & & \\
\hline & & & & $\mathbf{R}$ & $\mathbf{S}$ & $\mathbf{R}$ & $\mathbf{S}$ & & \\
\hline DeltaOPAL & $\mathrm{R}$ & 23 & $1: 0$ & 23 & 0 & 23 & 0 & & \\
\hline BRS Ita 90 & $\mathrm{~S}$ & 18 & $0: 1$ & 0 & 18 & 0 & 18 & & \\
\hline F 1 & $\mathrm{R}$ & 20 & $1: 0$ & 20 & 0 & 20 & 0 & & \\
\hline F 2 & Segreg & 127 & $3: 1$ & 95 & 32 & 95,25 & 31,75 & $0,0026 \mathrm{NS}$ & 94,91 \\
\hline
\end{tabular}

* $\mathrm{R}=$ Resistente; $\mathrm{S}=$ Suscetível; Segreg = Segregando; NS= não significativo $(p=0,5)$.

** Inoculação foi realizada em casa de vegetação, nas plântulas de 25 dias de idade, com isolado agressivo de Xam (nº 13403), e a reação das plantas foi observada 20 dias após a inoculação.

TABELA 2 - Teste de qui-quadrado para os padrões de segregação para área foliar infetada por Xanthomonas axonopodis pv. malvacearum (Xam), baseado nas reações dos progenitores e das populações segregantes do cruzamento EPAMIG Liça X BRS Ita 90

\begin{tabular}{|c|c|c|c|c|c|c|c|c|c|}
\hline \multirow{3}{*}{ População } & \multirow{3}{*}{$\begin{array}{l}\text { Reação } \\
\text { foliar* }\end{array}$} & \multirow{3}{*}{$\begin{array}{l}\mathrm{n}^{0} \text { total de } \\
\text { indivíduos }\end{array}$} & \multirow{3}{*}{$\begin{array}{c}\text { Razão teórica } \\
\text { (R:S) }\end{array}$} & \multicolumn{4}{|c|}{$\begin{array}{l}\text { Número de indivíduos em } \\
\text { cada categoria de infecção** }\end{array}$} & \multirow{3}{*}{2} & \multirow{3}{*}{ Prob \% } \\
\hline & & & & \multicolumn{2}{|c|}{ Observados* } & \multicolumn{2}{|c|}{ Esperados* } & & \\
\hline & & & & $\mathbf{R}$ & $\mathbf{S}$ & $\mathbf{R}$ & $\mathbf{S}$ & & \\
\hline EPAGIG Liça & $\mathrm{R}$ & 21 & $1: 0$ & 21 & 0 & 21 & 0 & & \\
\hline BRS Ita 90 & $\mathrm{~S}$ & 18 & $0: 1$ & 0 & 18 & 0 & 18 & & \\
\hline F 1 & $\mathrm{R}$ & 20 & $1: 0$ & 20 & 0 & 20 & 0 & & \\
\hline F 2 & Segreg & 129 & $3: 1$ & 96 & 33 & 96.75 & 32.25 & $0,232 \mathrm{NS}$ & 87,88 \\
\hline
\end{tabular}

* $\mathrm{R}=$ Resistente; $\mathrm{S}=$ Suscetível; Segreg = Segregando; NS = não significativo $(p=0,5)$.

** Inoculação foi realizada em casa de vegetação, nas plântulas de 25 dias de idade, com isolado agressivo de Xam (n 13403 ), e a reação das plantas foi observada 20 dias após a inoculação. 
de 3R: $1 \mathrm{~S}$ foi aceito pelo teste de $\chi 2(p=87,88 \%)$.

Todas as plantas da cv. resistente Fibermax 986 mostraram reação resistente dez dias após a inoculação com um isolado agressivo de Xam. Similarmente, todas as plantas da cv. suscetível BRS Ita 90 mostraram reação suscetível. As plantas da geração F1 mostraram resistência completa enquanto que, as plantas da geração F2 segregaram entre resistentes e suscetíveis. A hipótese de envolvimento de dois genes dominantes para resistência com a razão de segregação 9R:7S foi aceita pelo teste de $\chi 2$ (probabilidade $=63,26 \%$ ) (Tabela 3). Nesta cultivar a herança é condicionada por dois genes dominantes, complementares e independentes. Plantas que possuem apenas um dos genes são suscetíveis.

Os resultados obtidos no presente trabalho podem ser aproveitados nos programas de melhoramento que visam a criação de novas cultivares com resistência a mancha angular.

\section{AGRADECIMENTOS}

O presente trabalho foi realizado com o suporte financeiro de FACUAL, MT, e apoio técnico de Ademar Sabino de Souza.

TABELA 3 - Teste de qui-quadrado para os padrões de segregação para a área foliar infetada por Xamthomonas axonopodes pv. malvacearum (Xam), baseado nas reações dos progenitores e das populações segregantes do cruzamento Fibermax 986 X BRS Ita 90

\begin{tabular}{|c|c|c|c|c|c|c|c|c|c|}
\hline \multirow{3}{*}{ População } & \multirow{3}{*}{$\begin{array}{l}\text { Reação } \\
\text { foliar* }\end{array}$} & \multirow{3}{*}{$\begin{array}{l}\mathrm{n}^{0} \text { total de } \\
\text { indivíduos }\end{array}$} & \multirow{3}{*}{$\begin{array}{c}\text { Razão teórica } \\
\text { (R:S) }\end{array}$} & \multicolumn{4}{|c|}{$\begin{array}{l}\text { Número de indivíduos em } \\
\text { cada categoria de infecção** }\end{array}$} & \multirow{3}{*}{2} & \multirow{3}{*}{ Prob \% } \\
\hline & & & & \multicolumn{2}{|c|}{ Observados* } & \multicolumn{2}{|c|}{ Esperados* } & & \\
\hline & & & & $\mathbf{R}$ & $\mathbf{S}$ & $\mathbf{R}$ & $\mathbf{S}$ & & \\
\hline Fiber max - 986 & $\mathrm{R}$ & 10 & $1: 0$ & 10 & 0 & 10 & 0 & & \\
\hline BRS Ita - 90 & $\mathrm{~S}$ & 10 & $0: 1$ & 0 & 10 & 0 & 10 & & \\
\hline F1 & $\mathrm{R}$ & 85 & $1: 0$ & 85 & 0 & 85 & 0 & & \\
\hline $\mathrm{F} 2$ & Segreg. & 160 & $9: 7$ & 87 & 73 & 90 & 70 & $0,2285 \mathrm{NS}$ & 63,26 \\
\hline
\end{tabular}

\section{REFERÊNCIAS BIBLIOGRÁFICAS}

CIA, E. \& FUZATTO, M.G. Doenças do algodoeiro no Brasil. Anais, Congresso Internacional do Agronigócio do Algodão. Rondonópolis, Fundação MT/ Embrapa, 2000. pp.175-187.

FREIRE, E.C., FARIAS, F.J.C., AGUIAR, P. \& ARAÚJO, A. E. Comportamento de novas cultivares e linhagens com relação a doenças no Centro-Oeste-safra 1998/99. Anais, II Congresso
Brasileiro de Algodão, Riberão Preto, Embrapa-Algodão. 1999. pp.454-457.

MEHTA, Y.R., BOLOGNINI, V., BIBANCO, K.R.P., NUNES, M.P.B., AGUIAR, P., CIA, E., PIZINATTO, M.A. \& CHIAVEGATO. E.J. Resistência de cultivares do algodoeiro a mancha angular causada por Xanthomonas axonopodis pv. malvacearum Summa Phytopathologica 30:501-503. 2004. 